OPEN ACCESS

Edited by: Aleksandra M. Lewandowska University of Helsinki, Finland

Reviewed by:

Wenxue Wu

Sun Yat-sen University, China

Germo Väli,

Tallinn University of Technology,

Estonia

${ }^{*}$ Correspondence:

Thorsten Blenckner

Thorsten.blenckner@su.se

Specialty section:

This article was submitted to Global Change and the Future Ocean,

a section of the journa

Frontiers in Marine Science

Received: 22 July 2021 Accepted: 06 September 2021

Published: 01 October 2021

Citation:

Blenckner T, Ammar Y,

Müller-Karulis B, Nirranen $S$, Arneborg $L$ and $L i Q$ (2021) The Risk

for Novel and Disappearing

Environmental Conditions in the Baltic

Sea. Front. Mar. Sci. 8:745722.

doi: 10.3389/fmars.2021.745722

\section{The Risk for Novel and Disappearing Environmental Conditions in the Baltic Sea}

\author{
Thorsten Blenckner 1*, Yosr Ammar'1, Bärbel Müller-Karulis², Susa Niiranen', \\ Lars Arneborg ${ }^{3}$ and Qiang $\mathrm{Li}^{4}$
}

${ }^{1}$ Stockholm Resilience Centre, Stockholm University, Stockholm, Sweden, ${ }^{2}$ Baltic Sea Centre, Stockholm University, Stockholm, Sweden, ${ }^{3}$ Swedish Meteorological and Hydrological Institute, Norrköping, Sweden, ${ }^{4}$ Department of Physical Geography, Stockholm University, Stockholm, Sweden

Future climate biogeochemical projections indicate large changes in the ocean with environmental conditions not experienced at present referred to as novel, or may even disappear. These climate-induced changes will most likely affect species distribution via changes in growth, behavior, evolution, dispersal, and species interactions. However, the future risk of novel and disappearing environmental conditions in the ocean is poorly understood, in particular for compound effects of climate and nutrient management changes. We map the compound risk of the occurrence of future novel and disappearing environmental conditions, analyze the outcome of climate and nutrient management scenarios for the world's largest estuary, the Baltic Sea, and the potential consequences for three charismatic species. Overall, the future projections show, as expected, an increase in environmental novelty over time. The future nutrient reduction management that improves the eutrophication status of the Baltic Sea contributes to large novel and disappearing conditions. We show the consequences of novel and disappearing environmental conditions for fundamental niches of three charismatic species under different scenarios. This first step toward comprehensively analyzing environmental novelty and disappearing conditions for a marine system illustrates the urgent need to include novelty and disappearing projection outputs in Earth System Models. Our results further illustrate that adaptive management is needed to account for the emergence of novelty related to the interplay of multiple drivers. Overall, our analysis provides strong support for the expectation of novel ecological communities in marine systems, which may affect ecosystem services, and needs to be accounted for in sustainable future management plans of our oceans.

Keywords: novelty, rate of change, cumulative stressors, species distribution, disappearing conditions, management

\section{INTRODUCTION}

Future climate projections indicate that large land areas may undergo climate conditions not experienced at present, referred to as novel or no-analog climates, while other known climate conditions may disappear (Williams and Jackson, 2007; Mora et al., 2013). Likewise, the ocean is likely to experience large climate-induced changes, such as higher ocean temperatures, an increase 
in the number of marine heatwaves, changes in sea ice and sea level, and shifts in biogeochemical provinces (IPCC, 2019; Reygondeau et al., 2020).

These climate-induced compound events (Ridder et al., 2020) will most likely cause changes in physiological, behavioral, evolutionary, and dispersal characteristics of species, their absolute and relative abundances in addition to changes in their interactions (Lurgi et al., 2012; Blois et al., 2013; Pinsky et al., 2020). Niche theory predicts that species react individualistically to environmental changes resulting in sometimes unexpected changes in species distribution, disruption of existing communities, and formation of novel species associations, as experienced in the last deglaciation (Jackson and Overpeck, 2000; Williams and Jackson, 2007).

In addition, coastal areas and estuaries worldwide are largely affected by anthropogenic activities such as nutrient loads from land, fisheries, coastal constructions, maritime transport and activities, and hazardous substances (Blenckner et al., 2015; Halpern et al., 2015; Breitburg et al., 2018). Different combinations of these factors, together with climate-induced changes, are likely to further increase the rate of novel environmental conditions not experienced before, and the disappearance of some present environmental conditions. In the future, novel conditions may emerge in the tropics and in estuaries, such as the Baltic Sea (Reygondeau et al., 2020). In semi-enclosed seas, species are unlikely to shift to higher latitudes, due to the enclosed water body characteristics, and other environmental constraints such as salinity. This increases the risk of species extinction in these ecoregions.

To better understand the risk of future novel and disappearing conditions of estuarian ecosystems in the face of global climate change and anthropogenic pressure, we aim to study these potential future risks in the Baltic Sea, one of the world's largest semi-enclosed seas, located in Northern Europe. It is also one of the fastest-warming seas in the Northern Hemisphere (Rutgersson et al., 2014) and is affected by multiple anthropogenic pressures such as eutrophication, contamination by hazardous substances, and unsustainably high fishing intensity (Elmgren et al., 2015; Reusch et al., 2018). Earlier studies indicate that climate change, eutrophication, and overfishing, have resulted in structural and functional changes of food webs (Pecuchet et al., 2019; Törnroos et al., 2019), and ecosystem regime shifts in different parts of the Baltic Sea (e.g., Möllmann et al., 2009; Lindegren et al., 2012; Olsson et al., 2015; Eklöf et al., 2020). Recently, it has been found that novel biotic and abiotic conditions have increasingly appeared in the Baltic Sea in the past decades (Ammar et al., 2021). Future Baltic Sea projections indicate large increases in seawater temperature, decreases in salinity (Meier et al., 2012; Andersson et al., 2015; Saraiva et al., 2019) with severe changes in species and food-webs (Niiranen et al., 2013; Bauer et al., 2018, 2019). However, the risk of novel and disappearing environmental conditions in the future is yet to be analyzed.

Here, we map the compound risk of the occurrence of future novel and disappearing environmental conditions analyzing the outcome of climate and nutrient management scenarios for the Baltic Sea. We calculate three environmental risks indices (a) local change, (b) novel environmental conditions, and (c) disappearing environmental conditions at the Baltic Sea scale for two periods: the mid-future (2030-2049) and the far future (2080-2099). We then assess the contribution of salinity-, temperature-, and eutrophication-related factors to the emergence of future novelty in different scenarios. Finally, we explore the impact of novel and disappearing environmental conditions on the fundamental niches of three charismatic species.

\section{MATERIALS AND METHODS}

\section{Regional Climate Model Data}

We used the output from the biogeochemical model RCO (Rossby Centre Ocean model)-SCOBI, which consists of the physical Rossby Center Ocean (RCO) (Meier et al., 1999; Meier et al., 2003) and the Swedish Coastal and Ocean Biogeochemical (SCOBI) models (Eilola et al., 2009; Almroth-Rosell et al., 2011). RCO-SCOBI is a 3D model of the Baltic Sea with a $3.7 \mathrm{~km}$ horizontal (2 nautical miles) and $3 \mathrm{~m}$ vertical resolution. The model describes the dynamics of temperature, salinity, nitrate, ammonium, phosphate, three phytoplankton groups, zooplankton, detritus, and oxygen (Eilola et al., 2011; AlmrothRosell et al., 2015). Atmospheric forcings were generated by the regional model RCA4-NEMO (coupled Rossby Center Atmosphere Version 4 and Nucleus for European Modeling of the Ocean models (Dieterich et al., 2019; Gröger et al., 2019). An ensemble of four global circulation models (GCM) has been used and downscaled by the regional model RCA4-NEMO (Saraiva et al., 2019). Here, downscaled output from only one GCM was used, namely from the global Earth System Model MPI-ESM-LR (Max Planck Institute Earth System Model-Low Resolution ${ }^{1}$ ) with the purpose to focus on the approach of calculating novelty and disappearing environmental conditions. We are aware that other models from the ensemble members would show different results, but results from model A (i.e., MPI-ESM-LR) are very close to the ensemble mean in SST and at the lower (less extreme) range of salinity changes (Saraiva et al., 2019). The future projections were forced by two greenhouse gas (GHG) emission scenarios (Representative Concentration Pathways RCP 4.5 and RCP 8.5) and two nutrient load scenarios [Baltic Sea Action Plan (BSAP) and current reference load (REF)]. The REF load scenario assumes a future (2006-2098) land use and socioeconomic situation, and thereby nutrient load situation, that is unchanged compared to the historical period (1975-2005), but where nutrient loads can change due to changes in the climate and runoff, projected by the hydrological model E-HYPE (Hydrological Predictions for the Environment ${ }^{2}$, Hundecha et al., 2016). The BSAP load scenario assumes that nutrient sources are reduced following the BSAP nutrient reduction targets of the HELCOM Baltic Sea Action Plan, and maintained constant (independent of the runoff) at that level after 2020 (HELCOM, 2007; Gustafsson et al., 2011).

\footnotetext{
${ }^{1}$ https://www.mpimet.mpg.de

${ }^{2}$ http://hypeweb.smhi.se
} 
We analyzed the model output of ten environmental variables: sea surface and bottom temperature, sea surface and bottom salinity, bottom oxygen concentration, mixed layer depth (the depth at which the temperature deviated from the surface value by $0.5^{\circ} \mathrm{C}$, see Fu et al., 2012), halocline depth (calculated as the depth of the greatest salinity gradient, Väli et al., 2013), and winter nutrient (i.e., phosphate, nitrate, and ammonium) concentrations for each of the projection grid for the period 1975-2099.

\section{Local Change, Novelty, and Disappearing Environment Calculations}

We define three different time periods for our analysis: a historical period (1980-1999), a mid-future period (2030-2049) and a far-future period (2080-2099). Following the definitions used in Williams et al. (2007), the dissimilarities between different time periods are quantified by the Standardized Euclidean Distance (SED):

$$
S E D_{i j}=\sqrt{\sum_{k=1}^{n} \frac{\left(b_{k j}-a_{k i}\right)^{2}}{s_{k}^{2}}}
$$

where, $a_{k i}$ and $b_{k j}$ are the historical period and future period means for environmental variable $k$ at gridpoints $\mathrm{i}$ and $\mathrm{j}$ and $s_{k}$ is the standard deviation of variable $k$ for the historical period. We assume that changes in these ten variables together reflect important environmental conditions that are relevant for changes in the structures and functions of species in the Baltic Sea (Törnroos et al., 2019; Pecuchet et al., 2019).

Local change is calculated as change at each gridpoint, i.e., $\mathrm{i}=\mathrm{j}$. The novelty of the environment is calculated by comparing the environmental conditions in one of the future for each gridpoint to the historical period for all gridpoints and retaining the minimum SED. A high minimum SED indicates locations where the novelty in the future environment is high, i.e., future conditions bear little resemblance to historical (1980-1999) conditions at any location. Conversely, the level of disappearing environment is identified by comparing each gridpoint at a historical period to all gridpoints in both future periods and retaining the minimum SED. A high value in the novel environmental indicate places where the historical (19801999) environmental conditions may disappear, i.e., they have no close counterpart anywhere in the future simulations (Williams et al., 2007).

\section{Contribution to Novelty}

We categorized the contribution to novelty into three variable classes, (a) salinity-related factors (surface and bottom salinity, halocline depth), (b) temperature-related factors (surface and bottom temperature, mixing depth), and (c) eutrophicationrelated factors (phosphate, dissolved inorganic nitrogen, and bottom oxygen concentrations) for each scenario for mid- and far-future periods.

\section{Species Niches}

We explored the impact of novel and disappearing environmental conditions on the fundamental niches of three key species in the Baltic Sea, i.e., cod (Gadus morhua), eelgrass (Zostera marina L.) and starfish (Asterias rubens), to test in a simple way how they could be affected by the projected novel conditions. These three species are chosen as they are charismatic species that represent three trophic groups: (a) cod, a highly valued commercial fish species in the open Central Baltic Sea; (b) eelgrass, a macrophyte providing carbon storage and nursery habitats in coastal areas; and (c) starfish, a benthic species controlling for example blue mussel's population in the southern coastal areas. To estimate the fundamental niche of these three species, changes in the key variables (Table 1) affecting the species survival and distribution are plotted on spatial maps and niche space plots.

\section{RESULTS}

\section{Local Change, Novel, and Disappearing Conditions}

Local changes are primarily larger in the Northern basins. Under the RCP 4.5-BSAP scenario, the local changes in the dissimilarity

TABLE 1 | Species characteristics for cod, starfish, and eelgrass.

\begin{tabular}{|c|c|c|c|c|c|}
\hline Species & $\begin{array}{l}\text { Current } \\
\text { distribution }\end{array}$ & $\begin{array}{l}\text { Physiological } \\
\text { tolerances }\end{array}$ & Depth of occurrence & Model variables used & Source \\
\hline $\begin{array}{l}\text { Cod (Gadus morhua) } \\
\text { reproductive volume, } \\
\text { volume suitable for the } \\
\text { successful } \\
\text { development of the } \\
\text { early life stages }\end{array}$ & $\begin{array}{l}\text { Southern and } \\
\text { Central Baltic Sea }\end{array}$ & $\begin{array}{l}\text { Sal }>11 \mathrm{PSU} \text { and } \\
\text { oxygen }>2 \mathrm{ml} \mathrm{I}^{-1}\end{array}$ & Salinity above 11 PSU & $\begin{array}{l}\text { Suitable salinity and } \\
\text { oxygen for reproduction }\end{array}$ & $\begin{array}{l}\text { Nissling and Vallin, } \\
\text { 1996; Wikström et al., } \\
2016\end{array}$ \\
\hline $\begin{array}{l}\text { Eelgrass (Zostera } \\
\text { marina L.) }\end{array}$ & $\begin{array}{l}\text { Coastal areas of } \\
\text { the Baltic Sea }\end{array}$ & $\begin{array}{l}\mathrm{Sal}>5 \mathrm{PSU} \text { to } 15-25 \\
\mathrm{PSU} \text {, } \\
\text { temperature }>0 \mathrm{C}\end{array}$ & $\begin{array}{l}\text { Depth between } 1 \text { and } \\
10 \mathrm{~m} \text { depth }\end{array}$ & $\begin{array}{l}\text { Surface salinity vs. } \\
\text { surface temperature }\end{array}$ & $\begin{array}{l}\text { Boström et al., 2014; } \\
\text { Salo et al., } 2014\end{array}$ \\
\hline $\begin{array}{l}\text { Starfish (Asterias } \\
\text { rubens) }\end{array}$ & Southern Baltic Sea & $\begin{array}{l}\text { Sal }>8 \text { to } 36 \text { PSU \& All } \\
\text { ranges of Temperature } \\
\text { in the Baltic Sea }\end{array}$ & 20-90 m & $\begin{array}{l}\text { Bottom temperature } \\
\text { and salinity }\end{array}$ & Casties et al., 2015 \\
\hline
\end{tabular}

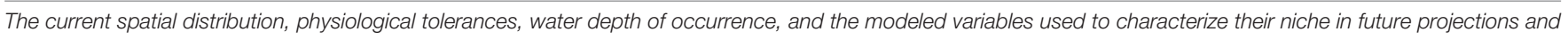
literature sources are presented. 
of all environmental variables together are first (2030-2049) high in the Northern Central basin and later (2080-2099) highest (>4 SED) in the Northern basins (Bothnian Bay and Sea), Central Baltic Sea, and Gulf of Finland, and decreases toward the south (Figures 1, 2). In contrast, the local change in the RCP 4.5REF scenario is in general lower than in the corresponding BSAP-scenario, except in Bothnian Bay and parts of the Western Central Baltic Sea in 2080-2099. While similar patterns as RCP4.5 were found under the RCP 8.5 scenarios for 2030-2049, local changes are largest ( $>4$ SED) for 2080-2099 in most of the Baltic Sea basins (except for Kattegat, the most south-western basin), independent of the nutrient load scenarios (Figures 1, 2). The highest absolute changes are found in the 2080-2099 period for the increases in surface water temperature (with up to $6^{\circ} \mathrm{C}$ in the RCP 8.5 ) and decreases in sea surface and bottom salinity by a Baltic Sea wide average decrease of -1.2 PSU (Figure 3). The 20 year-mean halocline depth increases by almost $3 \mathrm{~m}$ in the Central Baltic Sea in the RCP 8.5 scenario (2080-2099) compared to the historical period.
In both climate scenarios, local changes are larger in the BSAP scenarios than in the REF scenarios. In the BSAP scenarios, improving bottom oxygen concentrations (e.g., up to $2.2 \mathrm{ml} \mathrm{l}^{-1}$ in the Central Baltic and up to $1.8 \mathrm{ml}^{-1}$ in the Gulf of Finland by 2080-2099) as well as changing nutrient concentrations caused by the lower nutrient inputs, add to the climate-induced changes in water temperature and salinity. Bottom nitrate concentrations are increasing in the Central Baltic Sea (up to $3 \mathrm{mmol} \mathrm{m}^{-3}$ $\mathrm{NO}_{3}$, whereby bottom ammonium concentration is projected to decrease all over the Baltic Sea (mean $-1.4 \mathrm{mmol} \mathrm{m}^{-3} \mathrm{NH}_{4}$, largest in the Central Baltic, -3 to $-4 \mathrm{mmol} \mathrm{m}^{-3} \mathrm{NH}_{4}$ during 2080-2099). Surface nitrate concentration is increasing in the Northern basins (by $2.7 \mathrm{mmol} \mathrm{m}^{-3} \mathrm{NO}_{3}$ ), Gulf of Finland (2 to $2.7 \mathrm{mmol} \mathrm{m}^{-3} \mathrm{NO}_{3}$ ) and Riga (4.5-4.9 $\mathrm{mmol} \mathrm{m}{ }^{-3} \mathrm{NO}_{3}$ ) in both climate BSAP scenarios, whereby surface phosphorus concentration decreases over the whole Baltic Sea (mean 0.3 mmol $\left.\mathrm{m}^{-3} \mathrm{PO}_{4}\right)$. In the $\mathrm{REF}$ scenarios, an increase in the bottom oxygen concentrations in the Central Baltic Sea (around $1 \mathrm{ml} \mathrm{l}^{-1}$ ) and Gulf of Finland (around $1.3 \mathrm{ml} \mathrm{l}^{-1}$ ), together

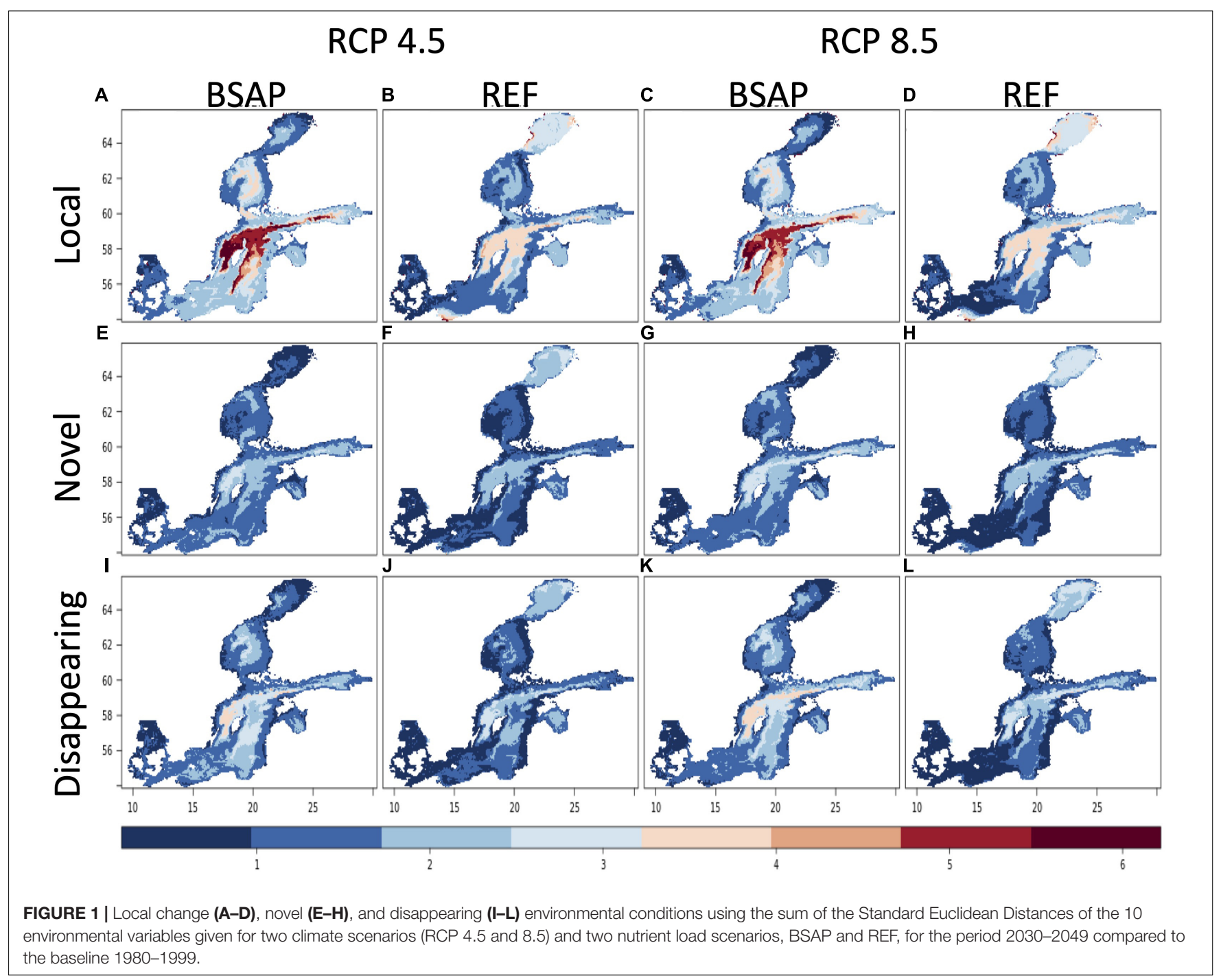




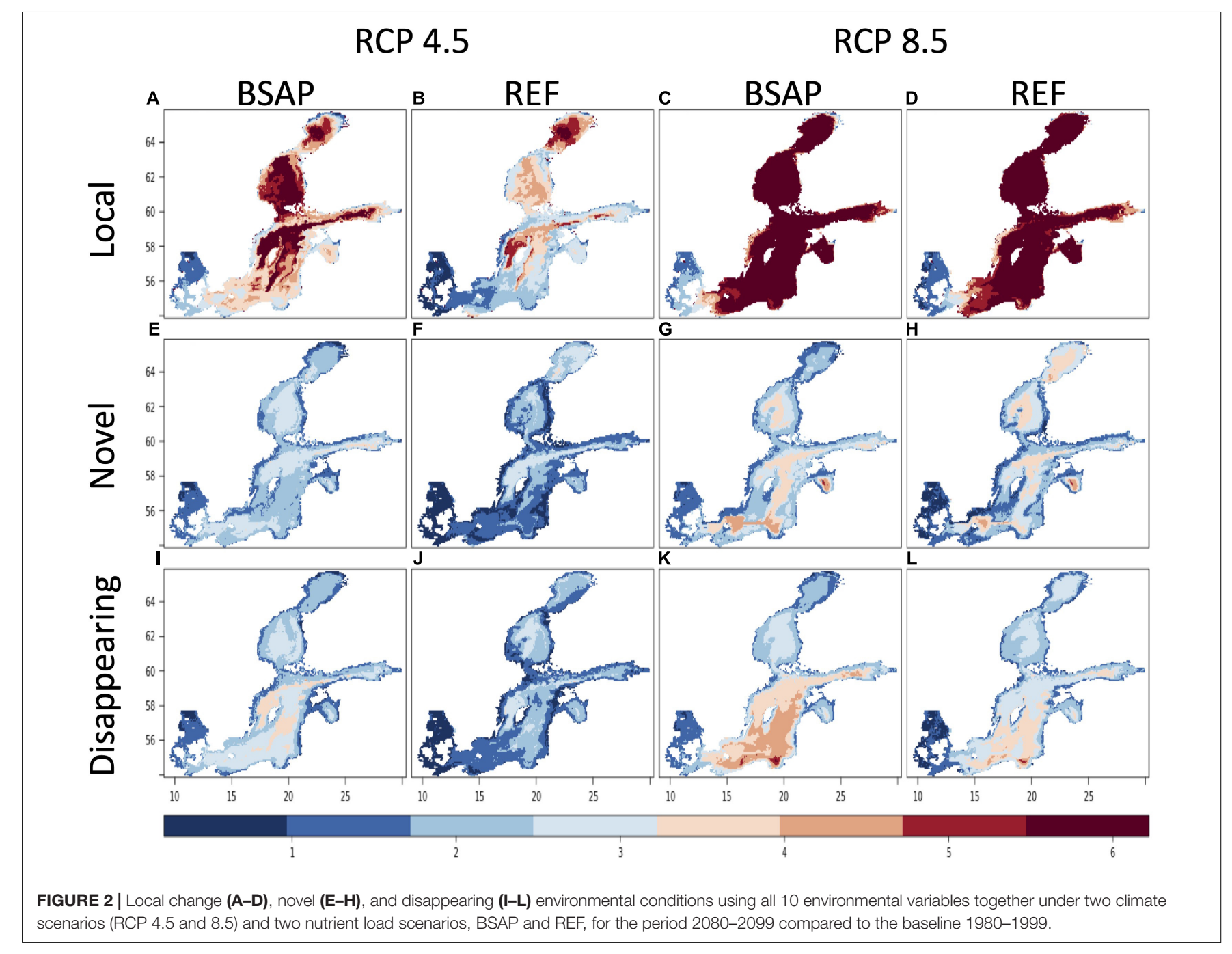

with decreases in bottom ammonium concentrations in the whole Baltic Sea (mean $-1 \mathrm{mmol} \mathrm{m}^{-3}$ ) were projected. Surface phosphorus concentrations are almost unchanged (Baltic Sea mean $-0.1 \mathrm{mmol} \mathrm{m}^{-3}$ ) in comparison to the $1980-1999$ period.

The degree of environmental novelty varies across the different scenarios. The highest novelty is calculated for the RCP 8.5 scenario for both nutrient load scenarios during the 2080-2099 period. As expected, novelty relative to the baseline (1980-1999) is always higher in 2080-2099 compared to the 2030-2049 period. For the BSAP scenario, the novelty is highest for the Gulf of Riga, Bothnian Sea and parts of the Central and Southern Baltic Sea, whereby the REF scenario projects less novelty in the Southern Baltic but higher novelty in the Bothnian Bay in comparison to the BSAP scenario (Figure 1). Under the RCP 4.5 and BSAP assumptions, a higher novelty than the RCP 4.5-REF scenario is projected due to the improving nutrient and oxygen conditions almost over the whole Baltic Sea.

The highest levels of disappearing environmental conditions (Figures 1, 2) occupy an area of the Gulf of Finland, Central and Southern Baltic Sea under RCP 8.5 scenarios during the 2080-2099 period (Figure 2). The highest values are calculated for the BSAP scenario, which has even higher dissimilarity values than under novel conditions. These disappearing conditions in the BSAP scenario are associated with the improvements and by that the disappearing of the hypoxic areas in combination with surface temperature increase and decrease of bottom salinity. The distribution of disappearing environments is lowest in the RCP 4.5-REF scenario.

Overall, differences between scenarios in the short-term are primarily due to differences between the nutrient scenario for the local change, novelty and disappearing conditions. However, in the long term, differences between the two climate scenarios become more pronounced.

\section{Contribution to Novelty Over Time}

The overall strongest contributors to novelty for the whole Baltic Sea change over time and depending on the scenario (Figure 4). During the 2030-2049 period, the eutrophication-related factors and temperature contribute most to novelty (Figure 4). For the BSAP scenarios, with higher change in nutrient and oxygen conditions, the contribution from the eutrophication factors dominate. For the REF scenarios, novelty is lower and is 


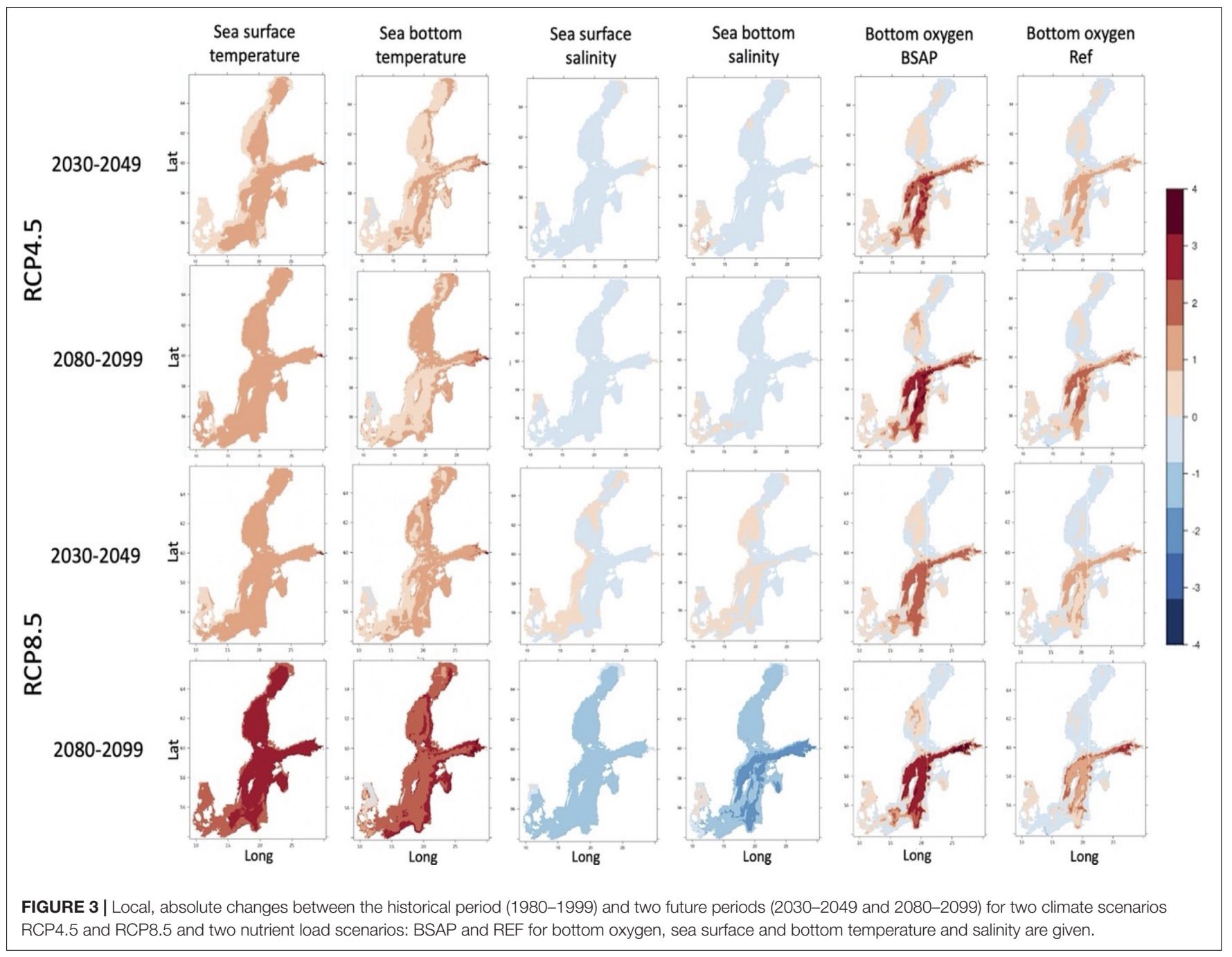

spread over eutrophication-, temperature- and partly salinityrelated factors. Spatially, the different factors are distributed heterogeneously over the entire Baltic Sea area. During the 20802099 period, the salinity contribution is increasing on top of the eutrophication and temperature-related factors, in particular for the two RCP-8.5 scenarios. Spatially, salinity contributes most to novelty in the southern Central Baltic Sea, whereby temperature contributes most in the North (Bothnian Sea) and in the deepest areas of the Central Baltic Sea.

\section{Potential Species Responses}

The projected changes of novel and disappearing environmental conditions affects the three key species fundamental niches differently. Cod (Gadus morhua) reproduction is primarily affected by the size of the RV. The two most contrasting projections indicate; (i) a larger RV with the RCP 4.5-BSAP scenario (Figure 5B), mainly caused by the improved bottom oxygen concentration in combination with minor decreases in salinity, or (ii) a reduced RV with the RCP 8.5-REF scenario (Figure 5B), mainly caused by larger decreases in bottom salinity ( $>4$ PSU) in combination with a minor increase in bottom oxygen concentration, in comparison to the historical conditions (Figure 5A).

Species-specific fundamental niche space for eelgrass (Zostera marina L.), calculated based on surface salinity and temperature, indicates minor changes (for spatial distribution see Supplementary Figure 1) between the historical and mid-future period (Figure 5D). In contrast, surface temperature is projected to increase largely in the RCP 8.5 scenario during the 2080-2099 period (Figure 5E), with substantially fewer areas suitable for seagrass (Supplementary Figure 2). For starfish (Asterias rubens) the future projected niche changes, calculated based on bottom salinity and bottom temperature, are even larger, in particular, due to changes in bottom temperature in both mid and far future periods (Figures 5F,G). If the starfish will not adapt to higher bottom temperatures and lower salinities, there might be a risk that this species will become extinct in the Baltic Sea, as the 2080-2099 conditions are outside the current reported niche space (Figure 5G). Spatially, less change is visible but most likely due to a vertical contracted range with acceptable bottom temperature and salinity conditions (Supplementary Figures 3, 4). 
RCP4.5
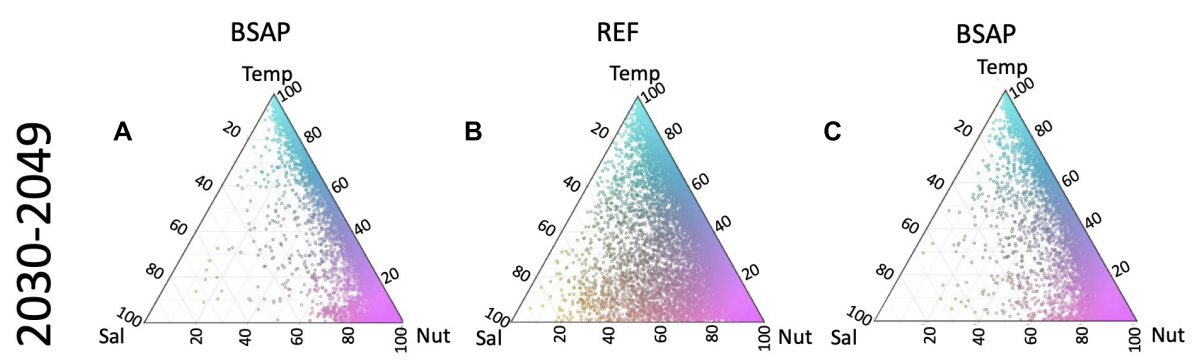

RCP8.5
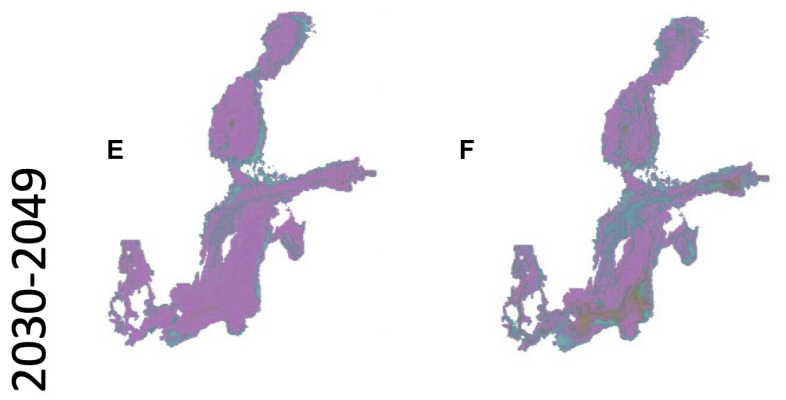

G

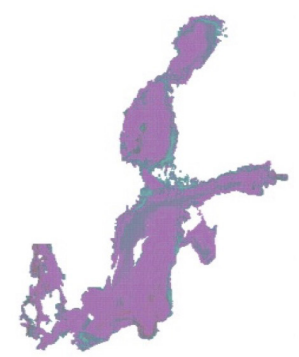

H
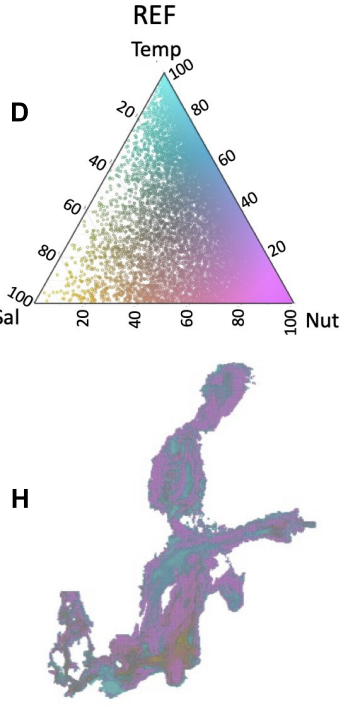
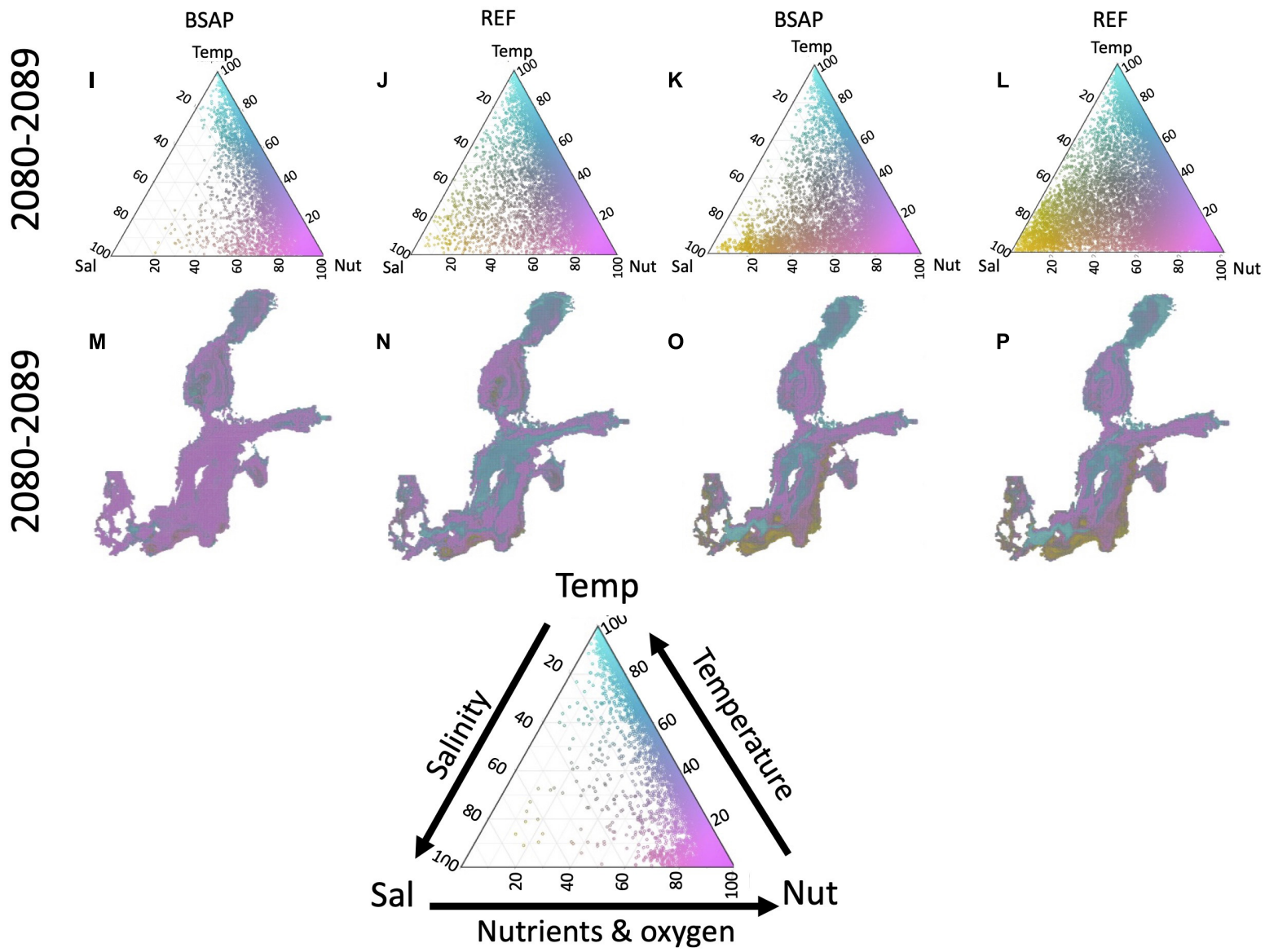

FIGURE 4 | The contribution of salinity (Sal, including surface and bottom salinity and halocline depth), temperature (Temp, including surface and bottom temperature and mixing depth), and nutrients and oxygen (Nut, including nutrients and bottom oxygen) related factors to total environmental novelty given for two climate scenarios (RCP 4.5 and 8.5) and two nutrient load scenarios, BSAP and REF, for 2030-2049 (A-H) and 2080-2099 period (I-P). In the bottom a triangle figure is presented to illustrate the interactions between the contribution components. 


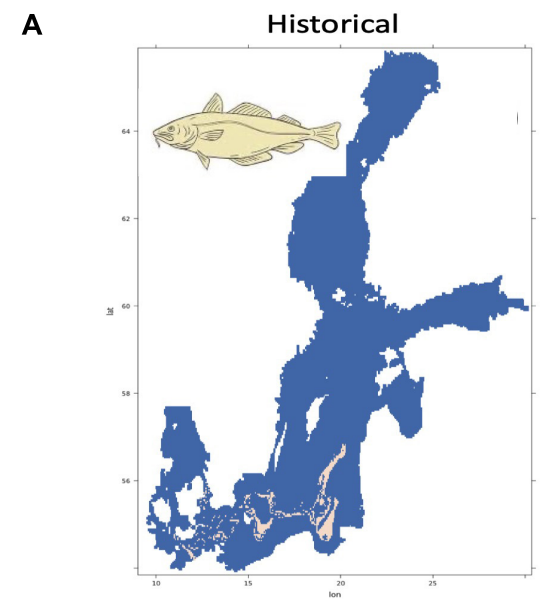

1980-1999

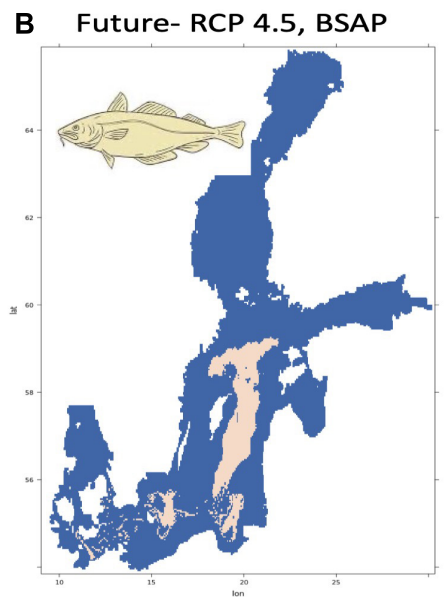

2080-2099

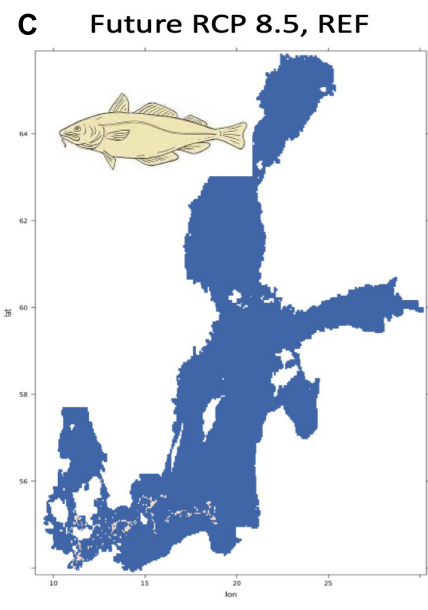

2080-2099
D

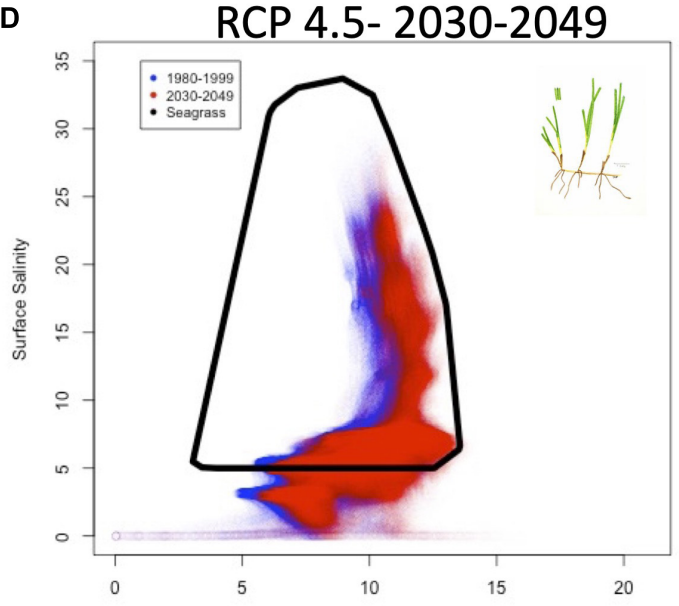

F

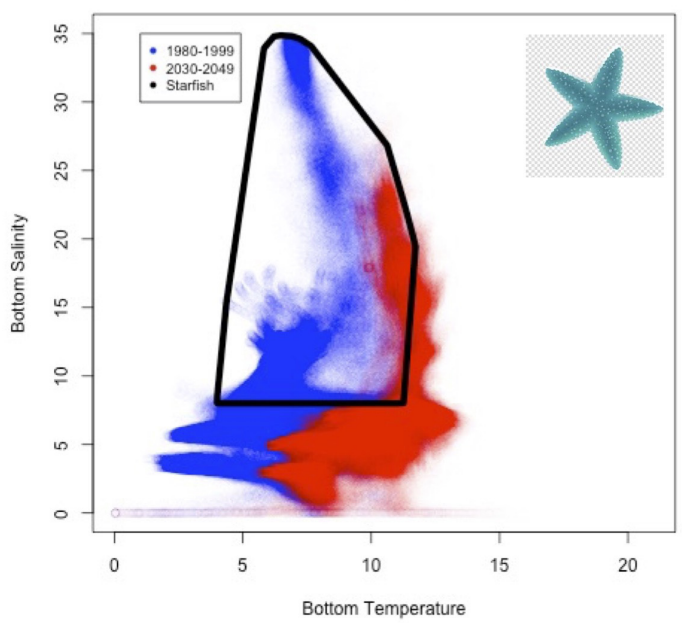

E

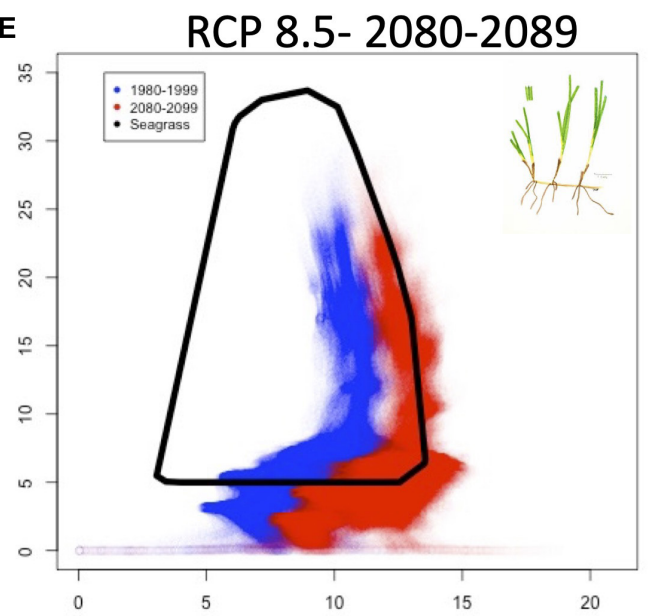

G

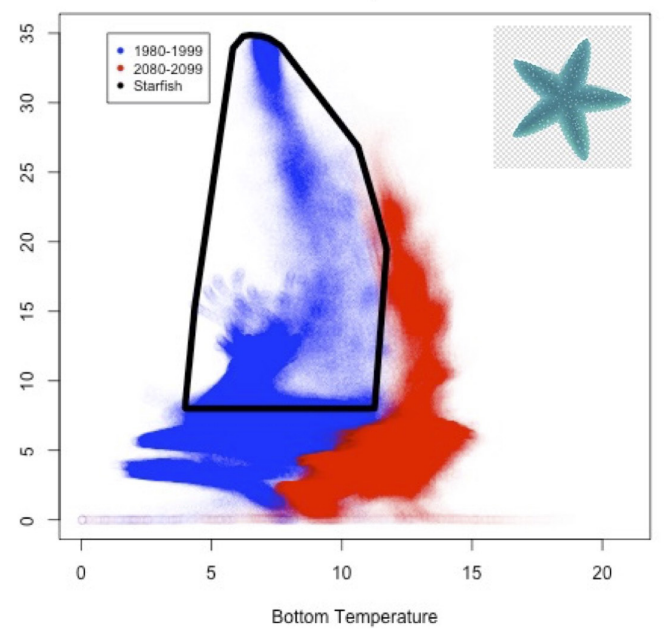

FIGURE 5 | Potential species responses to projected climate and nutrient scenarios. Changes of spatial mean cod reproductive volume projections (A-C) for the historical (1980-1999, A) and two future (2080-2099) scenarios, the RCP 4.5-BSAP (B), and RCP 8.5-REF (C). Niche dimensions are given for eelgrass with surface temperature and salinity (D,E) and for starfish with bottom temperature and salinity (F,G) for the 2030-2049 period (RCP 4.5; $\mathbf{D}, \mathbf{F})$ and for the 2080-2099 period (RCP 8.5, E,G). The current niche space is represented as black convex hull as well as the historical (1980-1999) annual means (blue data points) and future annual means in red (red data points are given for 2030-2049 range in panels D,F, 2080-2099 in panels E,G). 


\section{DISCUSSION}

Overall, the future projections show, as expected, an increase in novelty over time. The highest Baltic Sea-wide novelty is projected for both RCP 8.5 scenarios for the 2080-2099 period compared to the 1980-1999 baseline. Spatially the highest novelty is projected for the Bothnian Bay, Gulf of Riga and north to southern Central Baltic Sea (Figure 2) for the RCP 8.5BSAP scenario. For the RCP 8.5-REF scenario, the novelty is higher in the Bothnian Bay and slightly lower in the other basins than the RCP 8.5-BSAP scenario (Figure 2). However, the contributions to the novelty are somewhat different. In general, the decrease in salinity contributes to novelty in both RCP 8.5 scenarios. However, in the RCP 8.5-REF scenario, the temperature has the highest contribution. The latter corresponds well with the absolute changes of up to $6^{\circ} \mathrm{C}$ and decreases in sea surface and bottom salinity by a Baltic Sea-wide average of -1.2 PSU in the 2080-2099 period (Figure 3). Earlier studies have shown earlier pronounced warming during the summers in the northern Baltic Sea but with large overall uncertainties in the salinity projections (Meier et al., 2006, 2019; Saraiva et al., 2019).

The nutrient reduction management in the BSAP scenarios improves the eutrophication status of the Baltic Sea (Meier et al., 2019; Murray et al., 2019; Saraiva et al., 2019). For the RCP 8.5-BSAP scenario, the contribution to novelty is largely related to the reduction in nutrients (Figure 4). This is associated with the improvements of the bottom oxygen concentration in combination with surface temperature increase and bottom salinity decrease and likely affecting the cod distribution (Figure 5, see text below). Saraiva et al. (2019) found a decrease in primary production (-44\%), nitrogen fixation (-96\%), and hypoxic area (-32\%) under the RCP 4.5-BSAP scenario in comparison to the current conditions. These profound reductions explain why the nutrient reductions contribute primarily to the emergence of novel environmental conditions. Even larger changes have been found in the disappearing conditions, in particular for the far future period of the RCP 8.5-BSAP scenario for Gulf of Finland, Central, and Southern Baltic Sea (Figure 2). The highest disappearing environmental conditions are calculated for the BSAP scenario, considering the decrease of nutrient load, disappearing hypoxic condition, in addition to disappearing cool water temperature, and decreasing salinity.

\section{Species Responses}

Novel and disappearing environmental conditions will have consequences on species distributions, leading to a decrease in the overall spatial distribution for some species. In contrast, other species will expand their range, including invasive species (Pinsky et al., 2020). These changes will favor novel species interactions with consequences on ecosystem functions (Beaugrand et al., 2015; Poloczanska et al., 2016; Törnroos et al., 2019). Besides the gains and losses of certain species, changes in species abundances can be crucial. For instance, declines in abundances for thermally or salinity restricted species, especially in estuaries, may occur, owing to reduced performance and population declines as individuals die, fail to reproduce, or move to more suitable locations (Cheung et al., 2013; Bates et al., 2014; Antão et al., 2020). Additionally, in estuaries like the Baltic Sea, species range shifts are limited as, at some point, a physical boundary, i.e., land, limits further poleward distributions and the decrease in salinity may further constrain the distribution. Examples from other Estuaries showing distributional changes of zooplankton in the Gironde estuary (Chaalali et al., 2013), of fish in South African estuaries (James et al., 2013), or that a number of fish species associated to estuaries in European waters have migrated northward over the last 30 years (Nicolas et al., 2011).

In the Baltic, many marine species live at the lower range of their tolerance limits; hydrological factors mainly determine species' distribution and population size (Dutz and Christensen, 2018). Salinity is, thus, a fundamental factor determining on top of temperature the abundance and occurrence of species in the Baltic Sea (Möllmann et al., 2000; Viitasalo et al., 2015; Mäkinen et al., 2017). Around 8000 years ago, the Baltic Sea was colonized during the transformation of the post-glacial Ancylus Lake into the brackish water (Zillén et al., 2008), with some $10 \%$ of marine species present in the North Sea and beyond, establishing local populations (Johannesson and André, 2006). This colonization has been possible due to rather dramatic genetic shifts (Barth et al., 2019) and local adaptation (Leder et al., 2021). Besides, the thermal tolerance might depend on the life stage. For example, Dahlke et al. (2020) found that spawners and embryos are the most temperature-sensitive stages in the life cycle of fish. Some species may benefit from climate warming by exhibiting abundance increases and expanding their geographic ranges (Bates et al., 2014; Antão et al., 2020; Pinsky et al., 2020). Overall, the genetic behavioral, phenological adaptation potential is significant and determines how species will respond and adapt to future novel and disappearing environmental conditions.

In our simple projections for cod, the two most contrasting projections indicate either a larger RV with the RCP 4.5-BSAP scenario (Figure 5B), covering an area with high novel conditions mainly caused by the improved bottom oxygen concentration in combination with minor decreases in salinity. A reduced RV with the RCP 8.5-REF scenario (Figure 5B), covers an area with high disappearing conditions, i.e., decreases in bottom salinity ( $>4$ PSU) in combination with a minor increase in bottom oxygen concentration (Figure 3). Species-specific fundamental niche space for eelgrass indicates small changes between the historical and mid-future period (Figure 5D), whereby in particular surface temperature is projected to increase mainly in the RCP 8.5 scenario during the 2080-2099 period (Figure 5E). The latter changes could lead to smaller coastal habitat areas where eelgrass can survive. For starfish, the future projected niche changes are even larger, in particular, due to changes in bottom temperature in both mid and far future periods (Figures 5F,G). If the starfish do not adapt to higher bottom temperatures and lower salinities, there might be a risk that this species extinct in the Baltic Sea, as the 2080-2099 conditions are outside the current reported niche space (black convex hull, Figure 5G).

The novel conditions of lower production (BSAP scenarios) in combination with novel temperature and salinity conditions 
may also affect the species survival and species interactions, and overall habitat availability. In a few food-web model projection studies changes in habitat, biodiversity and species distribution in the Central Baltic Sea estimated that under the nutrient reduction scenario, the projected habitat and biodiversity are higher compared to the worst-case nutrient scenario. In the latter, the projected bottom oxygen concentrations are low, with severe consequences for benthic organisms (e.g., Saduria sp.) and adult cod habitat (loss of 25-75\%) (Bauer et al., 2018, 2019). These food-web projections are interesting and relevant but depend on today's assumptions of driver-species knowledge and therefore embed a considerable uncertainty. Kotta et al. (2019) used a different approach by linking experimental data with observations to create a species distribution model of two interacting species (a macroalga-herbivore association), and they find a decrease in both species due to salinity decreases, even if one is more salinity tolerant. This example nicely illustrates that it is essential to account for species interactions in future projections.

Overall, understanding the ecological impacts of novel environmental conditions will depend on (a) the fundamental niche of the species and if there is still room for adaptation, (b) if the change and rate to novel environmental conditions allow species to adapt, or (c) if the species cannot adapt and will eventually die (Oliver et al., 2019). Further, more knowledge on the species 'ability to cope with or adjust to changing environmental conditions, i.e., its adaptive capacity, is needed in general (Thurman et al., 2020) and in particular for the planning of specific management (e.g., design marine protected area network, Jonsson et al., 2020).

\section{Method Contributions and Limitations}

We are aware of the limitations using only one model scenario and not an ensemble of models (Williams and Jackson, 2007; Reygondeau et al., 2020), and by looking at 20-year averages, which is a short time interval relative to the time scales of natural variability in the system (e.g., Kniebusch et al., 2019). However, we attempted to illustrate that novelty and disappearing environmental conditions play an essential role in marine systems. They can have considerable consequences for species distribution and ecosystem function in the future, which could have implications for society. We are not using a threshold that distinguishes the novel from non-novel conditions (Williams and Jackson, 2007), which can be highly species- and context-specific (Figure 4). However, such thresholds would be important to define if the concept of novelty was to be used for concrete management purposes. We are aware that the dissimilarity approach (i.e., calculating SED) focusing on the Baltic Sea wide scale might be an abstract algorithm of novelty as different SEDs values can have different consequences for species. Therefore, it would be of high importance to develop more local "nonabstract" novelty indicators in future research that, at the same time, can also account for complexity, like multiple niche factors (Fitzpatrick et al., 2018). Further, no extreme events were considered as we calculated the SEDs based on average values of the whole period (e.g., 2080-2099), even though it is known that, for example, heatwaves can affect marine ecosystems largely (Frölicher and Laufkötter, 2018; Smale et al., 2019).

\section{CONCLUSION}

Our analysis provides a first step toward comprehensively analyzing environmental novelty and disappearing conditions for a marine system, and with this contributes to projected global studies that simulate changes in biogeochemical provinces and high novel conditions in the future (Reygondeau et al., 2020). As this study clearly shows, there is a risk for marine systems that due to novel and disappearing environmental conditions in the future, the species compositions and interactions will lack current analogs with consequences of further biodiversity loss and ecosystem services (e.g., fisheries). Therefore, there is an urgent need to support efforts that include novelty and disappearing projection outputs of Earth System Models, allowing a better understanding of how and where novel and disappearing environmental conditions might occur in marine ecosystems. Our results further show that adaptive management is needed to account for the emergence of novelty due to the interplay of multiple drivers, particularly climate-adaptive management actions on nutrient reductions and adjusting species-related baselines for management under novel and disappearing conditions. More research is needed to study compound effects of species in more detail to define more realistic management targets for the latter. Overall, our analysis provides strong support for the expectation of novel ecological communities in the marine system, which likely affects the services the ocean provides to humans and needs, therefore to be accounted for in sustainable management plans of our oceans.

\section{DATA AVAILABILITY STATEMENT}

The raw data supporting the conclusions of this article will be made available by the authors, without undue reservation.

\section{AUTHOR CONTRIBUTIONS}

TB designed the study and wrote the first draft of the manuscript. QL and YA pre-processed datasets and performed the numerical analyses. BM-K and LA provided expertise on biogeochemistry in the Baltic Sea. All authors made substantial contributions in the successive versions of the manuscript, read, and approved the submitted version.

\section{FUNDING}

This work was funded by the BONUS-BLUEWEBS Blue growth boundaries in novel Baltic food webs project, which has received funding from BONUS (Art 185), funded jointly by 
the EU, the Academy of Finland, Projektträger Jülich (PtJ), Germany, the State Education Development Agency of Latvia, the National Centre for Research and Development, Poland, and the Swedish Research Council Formas. TB has partly received funding from the European Union's Horizon 2020 Research and Innovation Program under grant agreement number 820989 (project COMFORT, Our common future ocean in the Earth system - quantifying coupled cycles of carbon, oxygen, and nutrients for determining and achieving safe operating spaces

\section{REFERENCES}

Almroth-Rosell, E., Eilola, K., Hordoir, R., Meier, H. E. M., and Hall, P. O. J. (2011). Transport of fresh and resuspended particulate organic material in the Baltic Sea - a model study. J. Mar. Syst. 87, 1-12. doi: 10.1016/j.jmarsys.2011.0 2.005

Almroth-Rosell, E., Eilola, K., Kuznetsov, I., Hall, P. O. J., and Meier, H. E. M. (2015). A new approach to model oxygen dependent benthic phosphate fluxes in the Baltic Sea. J. Mar. Syst. 144, 127-141. doi: 10.1016/j.jmarsys.2014.1 1.007

Ammar, Y., Niiranen, S., Otto, S. A., Möllmann, C., Finsinger, W., and Blenckner, T. (2021). The rise of novelty in marine ecosystems: the Baltic Sea case. Glob. Change Biol. 27:gcb.15503. doi: 10.1111/gcb.15503

Andersson, A., Meier, H. E. M., Ripszam, M., Rowe, O., Wikner, J., Haglund, P., et al. (2015). Projected future climate change and Baltic Sea ecosystem management. AMBIO 44, S345-S356. doi: 10.1007/s13280-015-0 654-8

Antão, L. H., Bates, A. E., Blowes, S. A., Waldock, C., Supp, S. R., Magurran, A. E., et al. (2020). Temperature-related biodiversity change across temperate marine and terrestrial systems. Nat. Ecol. Evol. 4, 927-933. doi: 10.1038/s41559-0201185-7

Barth, J. M. I., Villegas-Ríos, D., Freitas, C., Moland, E., Star, B., André, C., et al. (2019). Disentangling structural genomic and behavioural barriers in a sea of connectivity. Mol. Ecol. 28, 1394-1411. doi: 10.1111/mec.1 5010

Bates, A. E., Pecl, G. T., Frusher, S., Hobday, A. J., Wernberg, T., Smale, D. A., et al. (2014). Defining and observing stages of climate-mediated range shifts in marine systems. Glob. Environ. Change 26, 27-38. doi: 10.1016/j.gloenvcha. 2014.03.009

Bauer, B., Gustafsson, B. G., Hyytiäinen, K., Meier, H. E. M., Müller-Karulis, B., Saraiva, S., et al. (2019). Food web and fisheries in the future Baltic Sea. AMBIO 48, 1337-1349. doi: 10.1007/s13280-019-01229-3

Bauer, B., Meier, H. E. M., Casini, M., Hoff, A., Margoński, P., Orio, A., et al. (2018). Reducing eutrophication increases spatial extent of communities supporting commercial fisheries: a model case study. ICES J. Mar. Sci. 75, 1306-1317. doi: 10.1093/icesjms/fsy003

Beaugrand, G., Edwards, M., Raybaud, V., Goberville, E., and Kirby, R. R. (2015). Future vulnerability of marine biodiversity compared with contemporary and past changes. Nat. Clim. Change 5, 695-701. doi: 10.1038/nclimate 2650

Blenckner, T., Llope, M., Möllmann, C., Voss, R., Quaas, M. F., Casini, M., et al. (2015). Climate and fishing steer ecosystem regeneration to uncertain economic futures. Proc. R. Soc. B Biol. Sci. 282:20142809. doi: 10.1098/rspb.2014. 2809

Blois, J. L., Zarnetske, P. L., Fitzpatrick, M. C., and Finnegan, S. (2013). Climate change and the past, present, and future of biotic interactions. Science 341, 499-504. doi: 10.1126/science. 1237184

Boström, C., Baden, S., Bockelmann, A.-C., Dromph, K., Fredriksen, S., Gustafsson, C., et al. (2014). Distribution, structure and function of Nordic eelgrass (Zostera marina) ecosystems: implications for coastal management and conservation. Aquat. Conserv. Mar. Freshw. Ecosyst. 24, 410-434. doi: 10.1002/aqc. 2424

Breitburg, D., Levin, L. A., Oschlies, A., Grégoire, M., Chavez, F. P., Conley, D. J., et al. (2018). Declining oxygen in the global ocean and coastal waters. Science 359:eaam7240. doi: 10.1126/science.aam7240 with respect to tipping points) and partly from Formas ("When the sum is unknown" project).

\section{SUPPLEMENTARY MATERIAL}

The Supplementary Material for this article can be found online at: https://www.frontiersin.org/articles/10.3389/fmars. 2021.745722/full\#supplementary-material

Casties, I., Clemmesen, C., Melzner, F., and Thomsen, J. (2015). Salinity dependence of recruitment success of the sea star Asterias rubens in the brackish western Baltic Sea. Helgol. Mar. Res. 69, 169-175. doi: 10.1007/s10152-0150425-8

Chaalali, A., Chevillot, X., Beaugrand, G., David, V., Luczak, C., Boët, P., et al. (2013). Changes in the distribution of copepods in the Gironde estuary: a warming and marinisation consequence? Estuar. Coast. Shelf Sci. 134, 150-161. doi: 10.1016/j.ecss.2012.12.004

Cheung, W. W. L., Watson, R., and Pauly, D. (2013). Signature of ocean warming in global fisheries catch. Nature 497, 365-368. doi: 10.1038/nature12156

Dahlke, F. T., Wohlrab, S., Butzin, M., and Pörtner, H.-O. (2020). Thermal bottlenecks in the life cycle define climate vulnerability of fish. Science 369, 65-70. doi: 10.1126/science.aaz3658

Dieterich, C., Wang, S., Schimanke, S., Gröger, M., Klein, B., Hordoir, R., et al. (2019). Surface heat budget over the north sea in climate change simulations. Atmosphere 10:272. doi: 10.3390/atmos1005 0272

Dutz, J., and Christensen, A. M. (2018). Broad plasticity in the salinity tolerance of a marine copepod species, Acartia longiremis, in the Baltic Sea. J. Plankton Res. 40, 342-355. doi: 10.1093/plankt/fby013

Eilola, K., Gustafsson, B. G., Kuznetsov, I., Meier, H. E. M., Neumann, T., and Savchuk, O. P. (2011). Evaluation of biogeochemical cycles in an ensemble of three state-of-the-art numerical models of the Baltic Sea. J. Mar. Syst. 88, 267-284. doi: 10.1016/j.jmarsys.2011.05.004

Eilola, K., Meier, H. E. M., and Almroth, E. (2009). On the dynamics of oxygen, phosphorus and cyanobacteria in the Baltic Sea. A model study. J. Mar. Syst. 75, 163-184. doi: 10.1016/j.jmarsys.2008.08.009

Eklöf, J. S., Sundblad, G., Erlandsson, M., Donadi, S., Hansen, J. P., Eriksson, B. K., et al. (2020). A spatial regime shift from predator to prey dominance in a large coastal ecosystem. Commun. Biol. 3:459. doi: 10.1038/s42003-020-01 180-0

Elmgren, R., Blenckner, T., and Andersson, A. (2015). Baltic Sea management: successes and failures. AMBIO 44, 335-344. doi: 10.1007/s13280-015-0 653-9

Fitzpatrick, M. C., Blois, J. L., Williams, J. W., Nieto-Lugilde, D., Maguire, K. C., and Lorenz, D. J. (2018). How will climate novelty influence ecological forecasts? Using the quaternary to assess future reliability. Glob. Change Biol. 24, 3575-3586. doi: 10.1111/gcb.14138

Frölicher, T. L., and Laufkötter, C. (2018). Emerging risks from marine heat waves. Nat. Commun. 9:650. doi: 10.1038/s41467-018-03163-6

Fu, W., She, J., and Dobrynin, M. (2012). A 20-year reanalysis experiment in the Baltic Sea using three-dimensional variational (3DVAR) method. Ocean Sci. 18, 827-844.

Gröger, M., Arneborg, L., Dieterich, C., Höglund, A., and Meier, H. E. M. (2019). Summer hydrographic changes in the Baltic Sea, Kattegat and Skagerrak projected in an ensemble of climate scenarios downscaled with a coupled regional ocean-sea ice-atmosphere model. Clim. Dyn. 53, 5945-5966. doi: 10. 1007/s00382-019-04908-9

Gustafsson, B. G., Savchuk, O. P., and Meier, H. E. M. (2011). Load Scenarios for ECOSUPPORT Technical Report No. 4. Stockholm: Baltic Nest Institute, 18.

Halpern, B. S., Frazier, M., Potapenko, J., Casey, K. S., Koenig, K., Longo, C., et al. (2015). Spatial and temporal changes in cumulative human impacts on the world's ocean. Nat. Commun. 6:7615. doi: 10.1038/ncomms8615

HELCOM (2007). HELCOM Baltic Sea Action Plan. Helsinki: Helsinki Commission. 
Hundecha, Y., Arheimer, B., Donnelly, C., and Pechlivanidis, I. (2016). A regional parameter estimation scheme for a pan-European multi-basin model. J. Hydrol. Reg. Stud. 6, 90-111. doi: 10.1016/j.ejrh.2016.04.002

IPCC (2019). Special Report on the Ocean and Cryosphere in a Changing Climate. eds H.-O. Pörtner, D. C. Roberts, V. Masson-Delmotte, and P. Zhai. Cambridge: Cambridge University Press.

Jackson, S., and Overpeck, J. (2000). Responses of plant populations and communities to environmental changes of the late quaternary. Paleobiology 26, $194-220$.

James, N., van Niekerk, L., Whitfield, A., Potts, W., Götz, A., and Paterson, A. (2013). Effects of climate change on South African estuaries and associated fish species. Clim. Res. 57, 233-248. doi: 10.3354/cr01178

Johannesson, K., and André, C. (2006). INVITED REVIEW: life on the margin: genetic isolation and diversity loss in a peripheral marine ecosystem, the Baltic Sea. Mol. Ecol. 15, 2013-2029. doi: 10.1111/j.1365-294X.2006.02 919.x

Jonsson, P. R., Moksnes, P., Corell, H., Bonsdorff, E., and Nilsson Jacobi, M. (2020). Ecological coherence of marine protected areas: new tools applied to the Baltic Sea network. Aquat. Conserv. Mar. Freshw. Ecosyst. 30, 743-760. doi: $10.1002 / a q c .3286$

Kniebusch, M., Meier, H. E. M., Neumann, T., and Börgel, F. (2019). Temperature variability of the Baltic Sea since 1850 and attribution to atmospheric forcing variables. J. Geophys. Res. Oceans 124, 4168-4187. doi: 10.1029/2018JC01 3948

Kotta, J., Vanhatalo, J., Jänes, H., Orav-Kotta, H., Rugiu, L., Jormalainen, V., et al. (2019). Integrating experimental and distribution data to predict future species patterns. Sci. Rep. 9:1821. doi: 10.1038/s41598-018-38 416-3

Leder, E. H., André, C., Le Moan, A., Töpel, M., Blomberg, A., Havenhand, J. N., et al. (2021). Post-glacial establishment of locally adapted fish populations over a steep salinity gradient. J. Evol. Biol. 34, 138-156. doi: 10.1111/jeb.1 3668

Lindegren, M., Blenckner, T., and Stenseth, N. C. (2012). Nutrient reduction and climate change cause a potential shift from pelagic to benthic pathways in a eutrophic marine ecosystem. Glob. Change Biol. 18, 3491-3503. doi: 10.1111/j. 1365-2486.2012.02799.x

Lurgi, M., López, B. C., and Montoya, J. M. (2012). Novel communities from climate change. Philos. Trans. R. Soc. B Biol. Sci. 367, 2913-2922. doi: 10.1098/ rstb.2012.0238

Mäkinen, K., Vuorinen, I., and Hänninen, J. (2017). Climate-induced hydrography change favours small-bodied zooplankton in a coastal ecosystem. Hydrobiologia 792, 83-96. doi: 10.1007/s10750-016-3046-6

Meier, H., Döscher, R., Coward, A., Nycander, J., and Döös, K. (1999). RCO Rossby Centre Regional Ocean Climate Model: Model Description (version 1.0) and First Results From the Hindcast Period 1992/93. Reports Oceanography 26. Norrköping: SMHI.

Meier, H. E. M., Döscher, R. and Faxén, T. (2003). A multiprocessor coupled ice-ocean model for the Baltic Sea: application to salt inflow. J. Geophys. Res. 108:3273. doi: 10.1029/2000JC000521

Meier, H. E. M., Edman, M., Eilola, K., Placke, M., Neumann, T., Andersson, H. C., et al. (2019). Assessment of uncertainties in scenario simulations of biogeochemical cycles in the Baltic Sea. Front. Mar. Sci. 6:46. doi: 10.3389/fmars. 2019.00046

Meier, H. E. M., Kjellström, E., and Graham, L. P. (2006). Estimating uncertainties of projected Baltic Sea salinity in the late 21 st century. Geophys. Res. Lett. 33:L15705. doi: 10.1029/2006gl026488

Meier, H. E. M., Müller-Karulis, B., Andersson, H., Dieterich, C., Eilola, K., Gustafsson, B. G., et al. (2012). Impact of climate change on ecological quality indicators and biogeochemical fluxes in the Baltic Sea - a multi-model ensemble study. AMBIO 41, 626-636. doi: 10.1007/s13280-012-0325-y

Möllmann, C., Diekmann, R., Müller-Karulis, B., Kornilovs, G., Plikshs, M., and Axe, P. (2009). Reorganization of a large marine ecosystem due to atmospheric and anthropogenic pressure: a discontinuous regime shift in the Central Baltic Sea. Glob. Change Biol. 15, 1377-1393. doi: 10.1111/j.1365-2486.2008.01 814.x

Möllmann, C., Kornilovs, G., and Sidrevics, L. (2000). Long-term dynamics of main mesozooplankton species in the central Baltic Sea. J. Plankton Res. 22, 2015-2038.
Mora, C., Frazier, A. G., Longman, R. J., Dacks, R. S., Walton, M. M., Tong, E. J., et al. (2013). The projected timing of climate departure from recent variability. Nature 502, 183-187. doi: 10.1038/nature12540

Murray, C. J., Müller-Karulis, B., Carstensen, J., Conley, D. J., Gustafsson, B. G., and Andersen, J. H. (2019). Past, present and future eutrophication status of the Baltic Sea. Front. Mar. Sci. 6:2. doi: 10.3389/fmars.2019.0 0002

Nicolas, D., Chaalali, A., Drouineau, H., Lobry, J., Uriarte, A., Borja, A., et al. (2011). Impact of global warming on European tidal estuaries: some evidence of northward migration of estuarine fish species. Reg. Environ. Change 11, 639-649. doi: 10.1007/s10113-010-0196-3

Niiranen, S., Yletyinen, J., Tomczak, M. T., Blenckner, T., Hjerne, O., MacKenzie, B. R., et al. (2013). Combined effects of global climate change and regional ecosystem drivers on an exploited marine food web. Glob.Change Biol. 19, 3327-3342. doi: 10.1111/gcb.12309

Nissling, A., and Vallin, L. (1996). The ability of Baltic cod eggs to maintain neutral buoyancy and the opportunity for survival in fluctuating conditions in the Baltic Sea. J. Fish Biol. 48, 217-227. doi: 10.1111/j.1095-8649.1996.tb01114.x

Oliver, E. C. J., Burrows, M. T., Donat, M. G., Sen Gupta, A., Alexander, L. V., Perkins-Kirkpatrick, S. E., et al. (2019). Projected marine heatwaves in the 21 st century and the potential for ecological impact. Front. Mar. Sci. 6:734. doi: 10.3389/fmars.2019.00734

Olsson, J., Tomczak, M. T., Ojaveer, H., Gårdmark, A., Põllumäe, A., MüllerKarulis, B., et al. (2015). Temporal development of coastal ecosystems in the Baltic Sea over the past two decades. ICES J. Mar. Sci. 72, 2539-2548. doi: 10.1093/icesjms/fsv143

Pecuchet, L., Lindegren, M., Kortsch, S., Całkiewicz, J., Jurgensone, I., Margonski, P., et al. (2019). Spatio-temporal dynamics of multi-trophic communities reveal ecosystem-wide functional reorganization. Ecography 42, 1-12. doi: 10.1111/ ecog.04643

Pinsky, M. L., Selden, R. L., and Kitchel, Z. J. (2020). Climate-driven shifts in marine species ranges: scaling from organisms to communities. Ann. Rev. Mar. Sci. 12, 153-179. doi: 10.1146/annurev-marine-010419-010916

Poloczanska, E. S., Burrows, M. T., Brown, C. J., García Molinos, J., Halpern, B. S., Hoegh-Guldberg, O., et al. (2016). Responses of marine organisms to climate change across oceans. Front. Mar. Sci. 3:62. doi: 10.3389/fmars.2016.00062

Reusch, T. B. H., Dierking, J., Andersson, H. C., Bonsdorff, E., Carstensen, J., Casini, M., et al. (2018). The Baltic Sea as a time machine for the future coastal ocean. Sci. Adv. 4:eaar8195. doi: 10.1126/sciadv.aar8195

Reygondeau, G., Cheung, W. W. L., Wabnitz, C. C. C., Lam, V. W. Y., Frölicher, T., and Maury, O. (2020). Climate change-induced emergence of novel biogeochemical provinces. Front. Mar. Sci. 7:657. doi: 10.3389/fmars.2020. 00657

Ridder, N. N., Pitman, A. J., Westra, S., Ukkola, A., Hong, X. D., Bador, M., et al. (2020). Global hotspots for the occurrence of compound events. Nat. Commun. 11:5956. doi: 10.1038/s41467-020-19639-3

Rutgersson, A., Jaagus, J., Schenk, F., and Stendel, M. (2014). Observed changes and variability of atmospheric parameters in the Baltic Sea region during the last 200 years. Clim. Res. 61, 177-190. doi: 10.3354/cr01244

Salo, T., Pedersen, M., and Boström, C. (2014). Population specific salinity tolerance in eelgrass (Zostera marina). J. Exp. Mar. Biol. Ecol. 461, 425-429. doi: 10.1016/j.jembe.2014.09.010

Saraiva, S., Meier, H. E. M., Andersson, H., Höglund, A., Dieterich, C., Gröger, M., et al. (2019). Uncertainties in projections of the baltic sea ecosystem driven by an ensemble of global climate models. Front. Earth Sci. 6:244. doi: 10.3389/feart. 2018.00244

Smale, D. A., Wernberg, T., Oliver, E. C. J., Thomsen, M., Harvey, B. P., Straub, S. C., et al. (2019). Marine heatwaves threaten global biodiversity and the provision of ecosystem services. Nat. Clim. Change 9, 306-312. doi: 10.1038/ s41558-019-0412-1

Thurman, L. L., Stein, B. A., Beever, E. A., Foden, W., Geange, S. R., Green, N., et al. (2020). Persist in place or shift in space? Evaluating the adaptive capacity of species to climate change. Front. Ecol. Environ. 18:520-528. doi: 10.1002/fee. 2253

Törnroos, A., Pecuchet, L., Olsson, J., Gårdmark, A., Blomqvist, M., Lindegren, M., et al. (2019). Four decades of functional community change reveals gradual trends and low interlinkage across trophic groups in a large marine ecosystem. Glob. Change Biol. 25, 1235-1246. doi: 10.1111/gcb.14552 
Väli, G., Meier, H. E. M., and Elken, J. (2013). Simulated halocline variability in the Baltic Sea and its impact on hypoxia during 1961-2007. J. Geophys. Res. Oceans 118, 6982-7000. doi: 10.1002/2013JC009192

Viitasalo, M., Blenckner, T., Gårdmark, A., Kaartokallio, H., Kautsky, L., Kuosa, H., et al. (2015). "Environmental impacts-marine ecosystems," in Second Assessment of Climate Change for the Baltic Sea Basin, ed. The BACC II Author Team (Cham: Springer International Publishing), 363-380. doi: 10.1007/9783-319-16006-1_19

Wikström, A., Knape, J., Casini, M., Gårdmark, A., Cardinale, M., Hjelm, J., et al. (2016). Fishing, reproductive volume and regulation: population dynamics and exploitation of the eastern Baltic cod. Popul. Ecol. 58, 199-211. doi: 10.1007/ s10144-015-0520-3

Williams, J. W., and Jackson, S. T. (2007). Novel climates, no-analog communities, and ecological surprises. Front. Ecol. Environ. 5, 475-482. doi: 10.1890/070037

Williams, J. W., Jackson, S. T., and Kutzbach, J. E. (2007). Projected distributions of novel and disappearing climates by 2100 AD. PNAS 104, 5738-5742. doi: 10.1073/pnas.0606292104

Zillén, L., Conley, D. J., Andrén, T., Andrén, E., and Björck, S. (2008). Past occurrences of hypoxia in the Baltic Sea and the role of climate variability, environmental change and human impact. Earth Sci. Rev. 91, 77-92. doi: 10. 1016/j.earscirev.2008.10.001
Author Disclaimer: The work reflects only the author's view; the European Commission and their executive agency are not responsible for any use that may be made of the information the work contains.

Conflict of Interest: The authors declare that the research was conducted in the absence of any commercial or financial relationships that could be construed as a potential conflict of interest.

Publisher's Note: All claims expressed in this article are solely those of the authors and do not necessarily represent those of their affiliated organizations, or those of the publisher, the editors and the reviewers. Any product that may be evaluated in this article, or claim that may be made by its manufacturer, is not guaranteed or endorsed by the publisher.

Copyright (C) 2021 Blenckner, Ammar, Müller-Karulis, Niiranen, Arneborg and $\mathrm{Li}$. This is an open-access article distributed under the terms of the Creative Commons Attribution License (CC BY). The use, distribution or reproduction in other forums is permitted, provided the original author(s) and the copyright owner(s) are credited and that the original publication in this journal is cited, in accordance with accepted academic practice. No use, distribution or reproduction is permitted which does not comply with these terms. 